Tropical Journal of Pharmaceutical Research January 2021; 20 (1): 155-160

ISSN: $1596-5996$ (print); 1596-9827 (electronic) (C) Pharmacotherapy Group, Faculty of Pharmacy, University of Benin, Benin City, 300001 Nigeria.

\title{
Analysis of triterpenoids, carotenoids, and phenylpropanoids in the flowers, leaves, roots, and stems of white bitter melon (Cucurbitaceae, Momordica charantia)
}

\author{
Do Manh Cuong ${ }^{1}$, Ramaraj Sathasivam ${ }^{1}$, Chang Ha Park ${ }^{1}$, Hyeon Ji Yeo ${ }^{1}$, Ye \\ Eun Park ${ }^{1}$, Jae Kwang Kim ${ }^{2}$, Sang Un Park ${ }^{1,3 *}$ \\ ${ }^{1}$ Department of Crop Science, Chungnam National University, 99 Daehak-ro, Yuseong-gu, Daejeon 34134, ${ }^{2}$ Division of Life \\ Sciences, College of Life Sciences and Bioengineering, Incheon National University, 119 Academy-ro, Yeonsu-gu, Incheon \\ 22012, ${ }^{3}$ Department of Smart Agriculture Systems, Chungnam National University, 99 Daehak-ro, Yuseong-gu, Daejeon 34134, \\ Republic of Korea
}

*For correspondence: Email: supark@cnu.ac.kr; Tel: +82-42-821-5730

Sent for review: 31 July 2020

Revised accepted: 13 December 2020

\begin{abstract}
Purpose: To evaluate the contents of carotenoids, triterpenoids, and phenylpropanoids in different parts of white bitter melon.

Methods: We evaluated the accumulation of 2 triterpenoids, 10 carotenoids, and 11 phenylpropanoids in different parts of white bitter melon, including fruits at four different developmental stages using HPLC.

Results: Charantin, lutein, and rutin were the main triterpenoids, carotenoids, and phenylpropanoids, respectively. The accumulation of triterpenoids (momordicine and charantin), carotenoids (antheraxanthin, lutein, violaxanthin, $\alpha$-carotene, and $\beta$-carotene), and phenylpropanoids (caffeic acid, chlorogenic acid, epicatechin, gallic acid, p-coumaric acid, rutin, and trans-cinnamic acid) was high in the leaves and/or flowers, which are exposed to direct sunlight, but low in the roots.

Conclusion: Most of the analyzed components were accumulated at high levels in the leaves and/or flowers. These results will help exploit the compounds in various parts of white bitter melon that are beneficial for human health.
\end{abstract}

Keywords: Momordica charantia, Bitter melon, Triterpenoid, Carotenoid, Phenylpropanoid

\begin{abstract}
This is an Open Access article that uses a fund-ing model which does not charge readers or their institutions for access and distributed under the terms of the Creative Commons Attribution License (http://creativecommons.org/licenses/by/4.0) and the Budapest Open Access Initiative (http://www.budapestopenaccessinitiative.org/read), which permit unrestricted use, distribution, and reproduction in any medium, provided the original work is properly credited.
\end{abstract}

Tropical Journal of Pharmaceutical Research is indexed by Science Citation Index (SciSearch), Scopus, International Pharmaceutical Abstract, Chemical Abstracts, Embase, Index Copernicus, EBSCO, African Index Medicus, JournalSeek, Journal Citation Reports/Science Edition, Directory of Open Access Journals (DOAJ), African Journal Online, Bioline International, Open-J-Gate and Pharmacy Abstracts

\section{INTRODUCTION}

Bitter melon (Momordica charantia) is a popular herb used in traditional medicine in Asia, Africa, and the Caribbean. Bitter melon has been used to effectively treat several diseases such as sepsis, ulcers, viral infections, inflammations, diabetes, cancer, and human immunodeficiency virus infection [1-4]. Studies have shown that bitter melon is rich in carotenoids, terpenoids, essential oils, fatty acids, flavonoids, phenolic acids, proteins, and saponins [5], which are important components used in the pharmaceutical industry. 
Secondary metabolites such as stilbenes, carotenoids, flavonoids, monolignols, and various phenolic acids are derivatives and intermediate metabolites of phenylalanine [6]. These compounds play significant roles in plant growth and development, and protection against adverse biotic and abiotic stresses, such as UV irradiation, pollutants, infections, and herbivores. Furthermore, phenylpropanoids synthesized from phenylalanine play a significant role in plant defense, and synergism between plants and bacteria [4]. Carotenoid derivatives are pigments that accumulate in vegetables, flowers, and fruits, and they have been used to treat chronic and vascular diseases [7]. To date, over 1100 carotenoids have been identified in plants, and they are categorized into xanthophylls and carotenes $[8,9]$. In plants, carotenoids absorb light energy and protect chlorophyll from photodamage during photosynthesis $[9,10]$. Lutein, meso-zeaxanthin, and zeaxanthin are collectively called macular pigments, and are found in the human eye [11]. Vitamin $A$ is a group of unsaturated nutritional organic compounds and it is synthesized from the intermediary molecules of carotenoids ( $\alpha$ carotene, $\beta$-carotene, $\beta$-cryptoxanthin, and $\gamma$ carotene). In humans, vitamin A deficiency causes progressive eye diseases such as xerophthalmia and night blindness. Additionally, the intake of carotenoids helps reduce the risk of heart-related diseases, cancer, and cataract formation in humans $[12,13]$. Momordicin and charantin, two natural cucurbitane-type triterpenoids in plants, have been reported to exhibit potent hypoglycemic [14], potent anticancer, anti-diabetic, and anti-bacterial effects [5]. These triterpenoids have been found in the fruits, leaves, and seeds $[2,15]$ of bitter melon.

The gene expression levels of carotenoid, triterpenoid, and phenolic biosynthetic pathways in green bitter melon have been described $[1,3,4]$. However, similar information on white bitter melon is limited. In this study, we evaluated the accumulation of carotenoids, triterpenoids, and phenylpropanoids in different parts of white bitter melon, including fruits at four different developmental stages.

\section{EXPERIMENTAL}

\section{Plant materials}

Seeds of white bitter melon were provided by Beijing Namo Tech.-Trade Co. Ltd. (Beijing, China). After germination of the seeds in the laboratory, the seedlings were grown in a farm at Chungnam National University (Daejeon, Korea) for 90 days. Different parts of white bitter melon, including fruits at four different development stages (Figure 1), were collected. The collected samples were immediately transferred into liquid nitrogen and freeze-dried for $72 \mathrm{~h}$ at $-70^{\circ} \mathrm{C}$ for triterpenoid, carotenoid, and phenylpropanoid compound analysis.

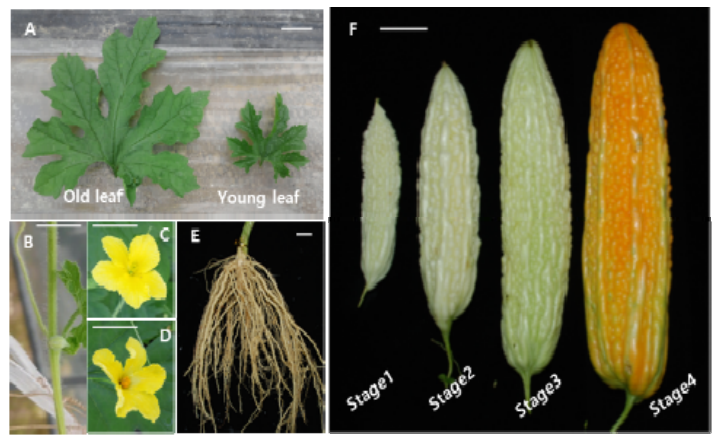

Figure 1: Phenotype of white bitter melon. Leaf (A), stem $(B)$, female flower $(C)$, male flower $(D)$, root $(E)$, and fruits at different developmental stages $(F)$. The scale bars represent $2.5 \mathrm{~cm}$

\section{Extraction and HPLC analysis of triterpenoids, carotenoids, and phenylpropa- noids in white bitter melon}

Triterpenoid compounds were extracted and analyzed using a previously described protocol [2]. The HPLC analysis, gradient program, and quantification of triterpenoids in white bitter melon were performed as per methods described by Cuong et al [2].

Carotenoid extraction and HPLC analysis were performed according to the protocol described by Cuong et al [1]. The HPLC conditions, gradient program, and quantification were according to the protocol described by Cuong et al [3] and Tuan et al [16].

Phenylpropanoid compounds were extracted and analyzed as per method described by Cuong et al [4]. The HPLC analysis, gradient program, and quantification of phenylpropanoids and flavonoids were performed as per procedures described by Cuong et al [4].

\section{Statistical analysis}

All data in this study were analyzed using the Statistical Analysis System software (SAS version 9.2, SAS Institute Inc., Cary, NC, USA, 2009) and expressed as mean $\pm S D$ of three biological replicates. The significant differences among the means were calculated using analysis of variance (ANOVA) with Duncan's Multiple Range Test (DMRT). 


\section{RESULTS}

\section{Triterpenoid content}

The accumulation of terpenoids in flowers (male and female flowers), leaves (young and mature leaves), roots, stems, and different stages of fruits was examined using HPLC. The momordicine content $(\mu \mathrm{g} / \mathrm{g}$ dry weight $(\mathrm{dw})$ ) was significantly high in the flowers; the male flowers had the highest content (42.34), followed by the female flowers (28.99) (Table 1). Momordicine accumulation was low in the roots, young leaves, and stage-1 fruits, whereas it was not detected in the stems, old leaves, and fruits (stages $2-4$ ). The accumulation of charantin in white bitter melon was highest in old leaves $(131.59 \mu \mathrm{g} / \mathrm{g}$ $d w)$, followed by stage-4 fruits and young leaves; its accumulation was low in the stems, flowers, and fruits (stages 1-3), whereas it was not detected in the roots. The accumulation of charantin increased significantly during the development of fruits, and was 130.76-, 21.15-, and 4.62-fold higher in stage 4 than that in stages $1-3$, respectively.

Table 1: Momordicin and charantin levels in different parts of white bitter melon ( $\mu \mathrm{g} / \mathrm{g} \mathrm{dw}$ )

\begin{tabular}{lcc}
\hline Variable & Momordicine & Charantin \\
\hline Root & $1.39 \pm 0.36 \mathrm{c}$ & $\mathrm{ND} \mathrm{f}$ \\
Stem & ND c & $2.33 \pm 0.7 \mathrm{f}$ \\
Young leaf & $0.77 \pm 0.082 \mathrm{c}$ & $43.37 \pm 8.8 \mathrm{c}$ \\
Old leaf & ND c & $131.59 \pm 8.4 \mathrm{a}$ \\
Female flower & $28.99 \pm 3.74 \mathrm{~b}$ & $10.49 \pm 2.5 \mathrm{e}$ \\
Male flower & $42.34 \pm 4.87 \mathrm{a}$ & $19.99 \pm 0.7 \mathrm{~d}$ \\
Stage-1 fruit & $0.05 \pm 0.015 \mathrm{c}$ & $0.38 \pm 0.03 \mathrm{f}$ \\
Stage-2 fruit & ND c & $2.349 \pm 0.012 \mathrm{f}$ \\
Stage-3 fruit & ND c & $10.75 \pm 0.4 \mathrm{e}$ \\
Stage-4 fruit & ND c & $49.69 \pm 4.123 \mathrm{~b}$ \\
\hline The mean and standard deviation values were \\
obtained from three biological replicates. ND: not \\
detected. Letters a-f denote significant differences $(p<$ \\
0.05)
\end{tabular}

\section{Carotenoid content}

The HPLC results of white bitter melon showed that the major carotenoids, lutein and $\beta$-carotene (13Z- $\beta$-carotene, 9Z- $\beta$-carotene, and E- $\beta$ carotene), were mostly present in the leaves, whereas lutein $(0.14 \mu \mathrm{g} / \mathrm{g} \mathrm{dw})$ was the only carotenoid present in the roots. However, its accumulation was significantly lower when compared to that in other parts. The accumulation of lutein was highest in old leaves (349.503 $\mu \mathrm{g} / \mathrm{g} \mathrm{dw}$ ), and was 1.76-, 3.69-, 6.4-, 7.09-, and 123.66-fold higher than that in the young leaves, stems, male flowers, female flowers, and roots, respectively. In fruits, the lutein level $(\mu \mathrm{g} / \mathrm{g} \mathrm{dw})$ was highest in stage 4 (12.43), followed by stage 1 (5.09), stage 2
(5.09), and stage 3 (5.12). Additionally, $\beta$ carotene accumulation (13Z- $\beta$-carotene, 9Z- $\beta$ carotene, and $E-\beta$-carotene) was highest in the leaves followed by the stems and flowers, whereas it was low in the fruits; it was undetectable in the roots. The E- $\beta$-carotene content was the highest in old leaves (194.096 $\mu \mathrm{g} / \mathrm{g} \mathrm{dw})$, and was 102.9-, 89.51-, 61.95-, 11.9-, 6.99-, 3.91-, 3.16-, and 1.73- fold higher than that in stage-2, stage-3, stage-1, and stage 4 fruits, female flowers, stems, male flowers, and young leaves, respectively. The accumulation of the isomers, 13Z- $\beta$-carotene and 9Z- $\beta$-carotene, was abundant in old leaves when compared to that in the other plant parts, and was low in the fruits; however, it was undetectable in the roots.

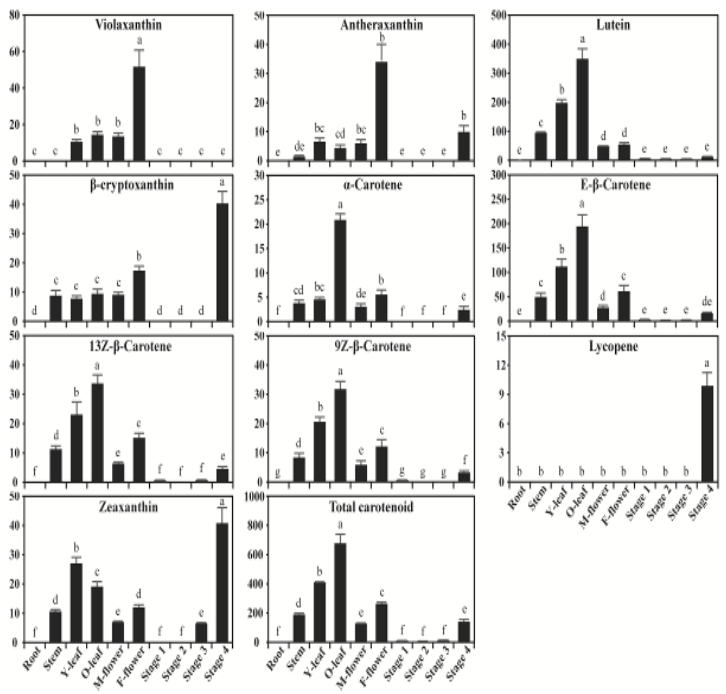

Figure 2: Carotenoid contents of different parts of white bitter melon $(\mu \mathrm{g} / \mathrm{g} \mathrm{dw})$. The mean and standard deviation values were obtained from three biological replicates. Y-leaves: Young leaves; O-leaves: Old leaves; F-flower: Female flower; M-flower: Male flower. Letters a-g denote significant differences $(p<0.05)$

The $\alpha$-carotene content $(\mu \mathrm{g} / \mathrm{g} \mathrm{dw})$ was highest in old leaves (20.86) followed by young leaves (4.54), male flowers (5.53), stems (3.77), female flowers (3.07), and stage-4 fruits (2.42). However, it was not detectable in the roots and fruits (stages 1-3). White bitter melon also contained a small amount of lycopene in stage-4 fruits; this was not detected in any of the other organs. The accumulation of violaxanthin and antheraxanthin was highest in male flowers and was low in the other plant segments. The $\beta$ cryptoxanthin content $(\mu \mathrm{g} / \mathrm{g} \mathrm{dw})$ was highest in stage-4 fruits (40.33) followed by male flowers (17.32), whereas it was low in the stems, leaves, and female flowers; it was not detectable in the roots and fruits (stages 1-3). In the fruits of white bitter melon, the contents of individual carotenoids were highest in stage 4, except that 
of violaxanthin, which was not detected in any of the fruit stages.

\section{Phenylpropanoid content}

The results of HPLC analysis showed that the contents of most phenylpropanoid compounds were highest in the organs (e.g., leaves, flowers, and stems), and lowest in the roots, except that of 4-hydroxybenzoic acid. p-Coumaric acid, chlorogenic acid, gallic acid, and rutin were accumulated more in the leaves than in the other organs (Figure 3).
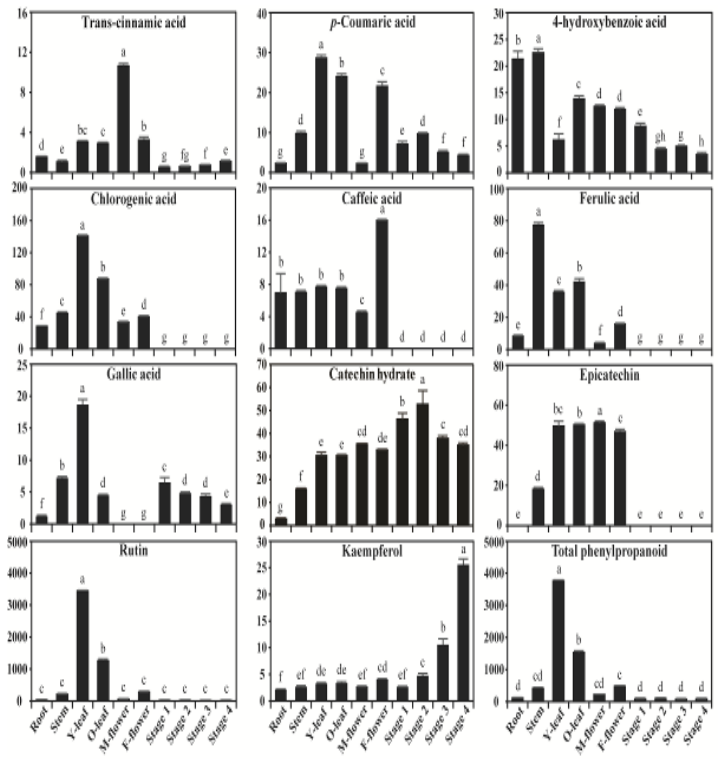

Figure 3: Phenylpropanoid contents in different parts of white bitter melon $(\mu \mathrm{g} / \mathrm{g} \mathrm{dw})$. The mean and standard deviation values were obtained from three biological replicates. Y-leaves: Young leaves; Oleaves: Old leaves; F-flower: Female flower; M-flower: Male flower. Letters a-h denote significant differences $(p<0.05)$

In fruits, only 4-hydroxybenzoic acid, catechin hydrate, gallic acid, kaempferol, p-coumaric acid, rutin, and trans-cinnamic acid were detected; specifically, the content of rutin and catechin hydrate were highest, followed by those of gallic acid, 4-hydroxybenzoic acid, p-coumaric acid, and kaempferol, whereas that of trans-cinnamic acid was the lowest. The amount of phenolic compounds varied between covering stages 1-3 to orange (stage 4). The contents of transcinnamic acid and kaempferol steadily increased in the four developmental stages and peaked in stage-4 fruits $(1.15$ and $25.61 \mu \mathrm{g} / \mathrm{g} \mathrm{dw}$, respectively). Contrarily, the accumulation of 4hydroxybenzoic acid was highest in stage-1 fruits, and then decreased, whereas the accumulation of rutin was found to be similar in the four stages of fruit development. The accumulation of $p$-coumaric acid and catechin hydrate increased and peaked in stage- 2 fruits, and then decreased in stages 3-4 fruits.

\section{DISCUSSION}

Several studies have revealed that triterpenoids exhibit potent anti-cancer, anti-diabetic, and antibacterial properties [5]. In this study, the contents of charantin and momordicine in white bitter melon were analyzed using HPLC (Table 1). Among the different fruits, stage-4 fruits showed the highest accumulation of charantin. This was in agreement with the findings of a previous study on green bitter melon; the charantin content significantly increased when the color of fruits changed from green (stages 1-3) to orange (stage 4) [2]. However, the accumulation of charantin $(\mu \mathrm{g} / \mathrm{g} \mathrm{dw})$ in stage-4 fruits of white bitter melon (49.69) was 2.68-fold higher than that in green bitter melon (18.50) [2]. Similar results have been reported; the charantin content was higher in the fruits than that in the leaves of the most green bitter melon cultivar [2,15]. However, in this study, the accumulation of charantin in old leaves was significantly higher than that in the fruits of white bitter melon.

In white bitter melon, most individual carotenoid contents were higher in the leaves when compared to that in the other parts. Similar results have been obtained for green bitter melon [1]. Additionally, the accumulation of $E-\beta-$ carotene and lutein was observed in all stages of fruit development, whereas antheraxanthin, lycopene, zeaxanthin, $\alpha$-carotene, and $\beta$ cryptoxanthin were found only in stage-4 fruits. Similar results were obtained in a previous study; a comparison of carotenoid accumulation in white and green bitter melon showed that green bitter melon accumulated higher carotenoid content [1]. In the present study, the carotenoid contents were relatively higher in the leaves, flowers, stems, and fruits; this might have been due to the exposure of these parts to direct sunlight. The roots were not exposed to sunlight; hence, the carotenoid accumulation was lower. Many studies have shown that in green bitter melon [1], Chinese cabbage [17], and Allium sativum [18], the carotenoid content is highest in the leaves, but is markedly in the roots. These results suggest that sunlight plays an important role in regulating the carotenoid pathway, which leads to the highest accumulation of carotenoids in white bitter melon.

The phenylpropanoid content was highest in the leaves, flowers, and stems of white bitter melon. This finding is similar to that observed for Lycium chinense [19] and Fagopyrum esculentum [20]. 
The contents of 4-hydroxybenzoic acid and ferulic acid were higher in the stems than those in the other organs, whereas the levels of caffeic acid and epicatechin were highest in the flowers. Most prior studies indicated that in green bitter melon [1], white mulberry [21], and L. chinense [19], the rutin content was highest in the leaves. Similarly, in this study, the rutin content was high in the young leaves $(3455.07 \mu \mathrm{g} / \mathrm{g} \mathrm{dw}$ ) of white bitter melon, and was 2.71-, 11.59-, 12.02-, 15.46-, 76.41-, 111.48-, 95.58-, 124.67-, and 114.81-fold higher than that in old leaves, female flowers, male flowers, stems, roots, and fruits (stages 1-4), respectively. The content of catechin hydrate and kaempferol were highest in the fruits.

\section{CONCLUSION}

Most triterpenoids, carotenoids, and phenylpropanoids are accumulated in high levels in the leaves and/or flowers of white bitter. These results indicate that sunlight may be one of the factors that regulate the triterpenoid, carotenoid, and phenylpropanoid content in white bitter melon. These findings will help exploit the compounds in white bitter melon that are beneficial for human health. Additionally, this study has provided valuable information for utilization of strategies to increase the level of various medicinal compounds in white bitter melon.

\section{DECLARATIONS}

\section{Acknowledgement}

This study was supported by the research fund from Chungnam National University in 2020.

\section{Conflict of interest}

No conflict of interest is associated with this work.

\section{Contribution of authors}

We declare that this work was done by the authors named in this article and all liabilities pertaining to claims relating to the content of this article will be borne by the authors. Do Manh Cuong and Ramaraj Sathasivam contributed equally to this work. Sang Un Park and Jae Kwang Kim designed the experiments and analyzed the data. Do Manh Cuong, Ramaraj Sathasivam, Chang Ha Park, Hyeon Ji Yeo, and Ye Eun Park performed the experiments and analyzed the data. Do Manh Cuong, Ramaraj
Sathasivam, and Sang Un Park wrote the manuscript. All authors read and approved the final manuscript.

\section{Open Access}

This is an Open Access article that uses a funding model which does not charge readers or their institutions for access and distributed under the terms of the Creative Commons Attribution License (http://creativecommons.org/licenses/by/ 4.0) and the Budapest Open Access Initiative (http://www.budapestopenaccessinitiative.org/rea d), which permit unrestricted use, distribution, and reproduction in any medium, provided the original work is properly credited.

\section{REFERENCES}

1. Cuong DM, Arasu MV, Jeon J, Park YJ, Kwon SJ, AlDhabi NA, Park SU. Medically important carotenoids from Momordica charantia and their gene expressions in different organs. Saudi J Biol Sci 2017a, 24: 1913-1919.

2. Cuong DM, Jeon J, Morgan AMA, Kim C, Kim JK, Lee $S Y$, Park SU. Accumulation of charantin and expression of triterpenoid biosynthesis genes in bitter melon (Momordica charantia). J Agr Food Chem 2017b, 65: 7240-7249.

3. Cuong DM, Kim JK, Jeon J, Kim TJ, Park JS, Park SU. Expression of carotenoid biosynthetic genes and carotenoid biosynthesis during seedling development of Momordica charantia. Nat Prod Commun 2018a, 13: 311-314.

4. Cuong DM, Kwon SJ, Jeon J, Park YJ, Park JS, Park SU. Identification and characterization of phenylpropanoid biosynthetic genes and their accumulation in bitter melon (Momordica charantia). Molecules 2018b, 23: 469.

5. Dandawate PR, Subramaniam D, Padhye SB, Anant S. Bitter melon: a panacea for inflammation and cancer. Chin J Nat Med 2016, 14: 81-100.

6. Liu JY, Osbourn A, Ma PD. MYB transcription factors as regulators of phenylpropanoid metabolism in plants. $\mathrm{Mol}$ Plant 2015, 8: 689-708.

7. Khoo HE, Prasad KN, Kong KW, Jiang YM, Ismail A. Carotenoids and their isomers: Color pigments in fruits and vegetables. Molecules 2011, 16: 1710-1738.

8. Yabuzaki J. Carotenoids Database: structures, chemical fingerprints and distribution among organisms. Database-Oxford 2017, 1-11.

9. Sathasivam R, Radhakrishnan R, Kim JK, Park SU. An update on biosynthesis and regulation of carotenoids in plants. S Afr J Bot 2020, 1-13.

10. Armstrong GA, Hearst JE, Carotenoids 2: Genetics and molecular biology of carotenoid pigment biosynthesis. FASEB J 1996, 10: 228-237.

11. Bernstein PS, Li B, Vachali PP, Gorusupudi A, Shyam R, Henriksen BS, Nolan JM. Lutein, zeaxanthin, and meso-

Trop J Pharm Res, January 2021; 20(1): 159 
zeaxanthin: The basic and clinical science underlying carotenoid-based nutritional interventions against ocular disease. Prog Retin Eye Res 2016, 50: 34-66.

12. Sathasivam R, Ki JS. A review of the biological activities of microalgal carotenoids and their potential use in healthcare and cosmetic industries. Mar Drugs 2018, 16: 26.

13. Sathasivam R, Radhakrishnan R, Hashem A, Abd Allah EF. Microalgae metabolites: $A$ rich source for food and medicine. Saudi J Biol Sci 2019, 26: 709-722.

14. Desai S, Tatke P. Charantin: An important lead compound from Momordica charantia for the treatment of diabetes. J Pharmacogn Phytochem 2015, 3: 4.

15. Goo KS, Ashari S, Basuki N, Sugiharto AN. The bitter gourd Momordica charantia L.: Morphological aspects, charantin and vitamin C contents. IOSR-JAVS 2016, 9: 6.

16. Tuan PA, Kim JK, Park NI, Lee SY, Park SU. Carotenoid content and expression of phytoene synthase and phytoene desaturase genes in bitter melon (Momordica charantia). Food Chem 2011b, 126: 1686-1692.

17. Tuan PA, Kim JK, Lee J, Park WT, Kwon do Y, Kim YB, Kim HH, Kim HR, Park SU. Analysis of carotenoid accumulation and expression of carotenoid biosynthesis genes in different organs of Chinese cabbage (Brassica rapa subsp. pekinensis). EXCLI J 2012, 11: 508-516.

18. Tuan PA, Kim JK, Kim HH. Lee SY, Park NI, Park SU. Carotenoid accumulation and characterization of cDNAs encoding phytoene synthase and phytoene desaturase in garlic (Allium sativum). J Agric Food Chem 2011, 59: 5412-5417.

19. Zhao S, Tuan PA, Li X, Kim YB, Kim H, Park CG, Yang J, $\mathrm{Li} \mathrm{CH}$, Park SU. Identification of phenylpropanoid biosynthetic genes and phenylpropanoid accumulation by transcriptome analysis of Lycium chinense. BMC Genomics 2013, 14: 802.

20. Li X, Park NI, XU H, Woo S, Park CH, Park SU. Differential expression of flavonoid biosynthesis genes and accumulation of phenolic compounds in common buckwheat (Fagopyrum esculentum). J Agric Food Chem 2010, 58: 12176-12181.

21. Zhao S, Park CH, Li X, Kim YB, Yang J, Sung GB, Park NI, Kim S, Park SU. Accumulation of rutin and betulinic acid and expression of phenylpropanoid and triterpenoid biosynthetic genes in mulberry (Morus alba L.). J Agric Food Chem 2015, 63: 8622-8630. 